\title{
Personality traits, coping strategies and nonspecific psychological distress: considerations for mental health in older adults
}

\begin{abstract}
The study of older adults has gained relevance in recent years. Although personality traits, coping strategies, and nonspecific psychological distress are related to mental health, they have not been studied in depth in this age group. The main purpose of this review was to address the interaction between these variables, considering adaptive and maladaptive aspects, and clarifying their specific characteristics in older adults. The current context of the COVID-19 pandemic represents a risk factor and a challenge for individuals in this age group, influencing both physical and mental health.
\end{abstract}

Keywords: older adults, stress, personality traits, coping strategies, nonspecific psychological distress
Volume 6 Issue 2 - 202 I

\author{
Garofalo Carolina Sofía,' Petrikovich Lucía,' \\ Garcia Claudia Silvina ${ }^{2}$ \\ 'Research Center in Psychology and Psychopedagogy, Pontifical \\ Catholic University of Argentina, Argentina \\ ${ }^{2}$ Faculty of Psychology, University of Aconcagua, Mendoza, \\ Argentina
}

\begin{abstract}
Correspondence: Carolina Sofia Garofalo, Licenciatura en Psicología, Pontificia Universidad Católica de Buenos Aires, Argentina. Ciudad Autónoma de Buenos Aires, Buenos Aires, Argentina, Tel +549II589333/5,

Email carolinasgarofalo@gmail.com
\end{abstract}

Received: March 10, 202I | Published: March 30, 202 I

\section{Introduction}

Aging leads to physical, cognitive, emotional and social changes manifested in a heterogeneous way and exposes the elderly to stressful situations. ${ }^{1}$ The way in which these modifications are experienced differs according to multiple factors, including personality and coping, facing a more or less stressful environment, ${ }^{2}$ which could be related to different levels of psychological distress. In addition, the current context of the COVID-19 pandemic has particularly affected the physical and mental health of older adults, representing a risk factor for the development of symptoms of anxiety and depression. ${ }^{3}$

Personality traits reflect characteristic patterns of thoughts, feelings, and behaviors, and imply consistency and stability across different situations and over time. ${ }^{4}$ The Big Five Factor Model ${ }^{5}$ proposes five personality traits: neuroticism, extraversion, openness to experience, agreeableness, and conscientiousness. Neuroticism is considered maladaptive per se, and high levels indicate greater anxiety, sadness, emotional instability, impulsivity and vulnerability; on the other hand, high degrees in the remaining traits involve mostly adaptive aspects. ${ }^{6-8}$ This model ${ }^{5}$ states that personality is made up of traits that remain relatively stable throughout the life cycle, particularly from 30 to 60 years. In old age, this stability gradually decreases, leading to changes, without existing a widespread consensus about the way in which the traits behave in this age group., ${ }^{9,10}$

Coping strategies to stress include cognitive and behavioral efforts developed to manage and tolerate internal and/or external demands -stressors-, whose approach is evaluated as exceeding of the individual's resources. ${ }^{11}$ Active forms of coping, which involve direct efforts to resolve a conflictive event, are usually described as successful and adaptive. On the contrary, passive forms imply the absence of confrontation and avoidance behaviors, considered less successful and maladaptive. ${ }^{12}$ However, its effectiveness varies depending on the stressful situation occurred and the persons' available means, resulting in more or less adaptive coping..$^{13}$ No consensus has been found on the use of coping strategies since the predominant trends and its evolution in older adults has not yet been determined. ${ }^{14}$ Nonspecific psychological distress includes physical, cognitive, emotional, and behavioral symptoms which are common to a variety of mental and psychiatric disorders; in other words, not specific to a single psychopathological disorder ${ }^{15}$ It is considered a state of emotional suffering characterized by anxious and depressive symptoms, ${ }^{16}$ hindering the adequate response to vital demands and social development and interaction. ${ }^{17}$ Due to the heterogeneity of aging, older adults may experience varied degrees of psychological distress, from healthy aging patterns with absence of distress symptoms, to psychopathological ways of aging with the presence of symptoms that increase in intensity and frequency, resulting in diagnostics of mental disorders, such as anxiety and depression..$^{18,19}$

These multiple psychological variables that intervene in old age demonstrate the complexity of late adulthood. The purpose of this work is to expose the relationship between the previous variables and their particularities in older adults, also taking into account the current context of COVID-19, contributing to knowledge in the scientific field and improvement of mental health.

\section{Relationship between personality traits, coping strategies and nonspecific psychological distress}

Some authors propose a theoretical association between personality, coping and psychological distress. Despite the flexibility in the use of coping strategies, there is a tendency to use more frequently those associated with personality predispositions, ${ }^{6,20,21}$ considering that personality is more stable than coping. ${ }^{22}$ Furthermore, the presence of anxious and depressive symptoms reflect maladaptive ways of coping with stressful situations. ${ }^{16}$ Although a small number of studies explored the relationship between these variables in older adults, the most relevant results of recent investigations are presented below.

It has been proven that higher levels of neuroticism indicate a predominant use of ineffective coping, while lower levels of this trait are related to the use of adaptive and successful strategies. These considerations reflect neuroticism as a maladaptive trait, associated 
with the absence of resolutive behaviors and inappropriate handling of the source of stress. On the contrary, higher levels of extraversion, agreeableness and conscientiousness involve less use of maladaptive strategies, which is considered an indicator of successful adaptation and mental health. ${ }^{16}$

Active and stressor-directed coping strategies are associated with fewer symptoms of distress, while passive and avoidant coping is associated with higher levels of psychological distress. ${ }^{23}$

Finally, personality is related to psychological distress in adults, including older adults; while neuroticism is positively correlated with anxious and depressive symptoms, the remaining personality traits are associated with lower levels of psychological distress. ${ }^{24-26}$

To conclude, coping strategies could be considered as an internal mediator between personality traits and psychological distress in adults ${ }^{27}$ and between stress and psychological distress in older adults. ${ }^{23}$ Therefore, personality influences the use of more or less adaptive coping strategies, affecting the levels of psychological distress experienced. Further studies of these variables may be relevant to clarify the behavior of older adults in the current context of the pandemic, promoting the creation of specific interventions that contribute to mental health.

\section{Conclusion}

This review evidences the relationship between personality traits, coping strategies and nonspecific psychological distress in older adults. The way in which these variables interact will result in a more or less effective adaptation to changes and diverse situations that occur in old age, influencing mental health.

The COVID-19 pandemic has affected all age groups worldwide, but particularly the elderly, considered a high-risk group due to their physical and mental vulnerability. As a result, strong measures were implemented to prevent the virus spread, such as social restraints, social distancing and strict quarantine, which have increased concerns about mental health in older adults. ${ }^{28}$ The worldwide occurrence of infectious diseases is closely related to symptoms of psychological distress, as well as physical and psychological pathologies, ${ }^{29}$ with a prevailing influence on mental health. ${ }^{30}$ During the current pandemic, a large number of older adults have experienced symptoms of distress, including anxiety, depression, and stress; additionally, this emotional response was more noticeable than other age groups. ${ }^{28}$

Bearing in mind this sanitary context, it is considered of the utmost importance to generate mental health interventions aimed at older adults, particularly for those with a greater prevalence of neuroticism, passive coping and psychological distress, characteristics whose maladaptive effects could be accentuated at a time of great global crisis and vulnerability, in order to promote a better quality of life and a healthier longevity.

\section{Acknowledgments}

None.

\section{Conflicts of interest}

The authors declare that there is no conflict of interest.

\section{References}

1. Byles JE, Gallienne L, Blyth FM, et al. Relationship of age and gender to the prevalence and correlates of psychological distress in later life. International Psychogeriatrics. 2012;24(6):1009-1018.
2. Ocampo Chaparro JM, Londoño IA. Ciclo vital individual: vejez. Revista de la Asociación Colombiana de Gerontología y Geriatría. 2007;21(3):1072-1084.

3. Mariani R, Renzi A, Di Trani M, et al. The impact of coping strategies and perceived family support on depressive and anxious symptomatology during the coronavirus pandemic (COVID-19) lockdown. Frontiers in Psychiatry. 2020;11:1195.

4. Diener E, Lucas RE. Personality traits. In: Biswas-Diener R, Brewer L, editors. general psychology: required reading. champaign. $D E F$ Publishers. 2019;278-296.

5. McCrae RR, Costa PTJr. A five-factor theory of personality. In: Pervin LA, John OP, editors. Handbook of personality: Theory and research. New York: Guildford Press; 2008;139-153.

6. Meléndez JC, Satorres E, Delhom I. Personality and coping. What traits predict adaptive strategies?. Anales de psicología. 2020;36(1):39-45.

7. Denburg N, Weller J, Yamada T, et al. Poor decision making among older adults is related to elevated levels of neuroticism. Annals of behavioral medicine: a publication of the Society of Behavioral Medicine. 2009;37:164-172.

8. Kaiseler M, Polman RCJ, Nicholls AR. Effects of the Big Five personality dimensions on appraisal coping, and coping effectiveness in sport. European Journal of Sport Science. 2012;12(1):62-72.

9. Lucas RE, Donnellan MB. Personality development across the life span: longitudinal analyses with a national sample from Germany. Journal of Personality and Social Psychology. 2011;101(4): 847-861.

10. Specht J, Luhmann M, Geiser C. On the consistency of personality types across adulthood: latent profile analyses in two large-scale panel studies. Journal of Personality and Social Psychology. 2014;107(3):540-556.

11. Folkman S, Lazarus RS, Dunkel-Schetter C, et al. Dynamics of a stressful encounter: cognitive appraisal, coping, and encounter outcomes. Journal of Personality and Social Psychology. 1986;50(5):992-1003.

12. Krzemien D, Monchietti A, Urquijo S. Afrontamiento activo y adaptación al envejecimiento en mujeres de la Ciudad de Mar del Plata: una revisión de la estrategia de autodistracción. Interdisciplinaria. 2005;22(2):183210 .

13. Amirkhan J, Auyeung B. Coping with stress across the lifespan: Absolute vs. relative changes in strategy. Journal of Applied Developmental Psychology. 2007;28(4):298-317.

14. Brennan P, Holland J, Schutte K, et al. Coping trajectories in later life: A 20-year predictive study. Aging and Mental Health. 2012;16:305-316.

15. Kessler RC, Andrews G, Colpe L, et al. Short screening scales to monitor population prevalences and trends in non-specific psychological distress. Psychological Medicine. 2002;32(6):959-976.

16. Drapeau A, Beaulieu-Prévost D, Marchand A, et al. A life-course and time perspective on the construct validity of psychological distress in women and men. Measurement invariance of the K6 across gender. BMC Medical Research Methodology. 2010;10(1):68-83.

17. Amadasi E. Estado, atención y necesidades de salud. In: Amadasi E, Tinoboras C, editors. Condiciones de vida e integración social de las personas mayores: ¿diferentes formas de envejecer o desiguales oportunidades de lograr una vejez digna?. Buenos Aires, Argentina: EDUCA. 2015;91-110.

18. Ayuso-Mateos JL, Nuevo R, Verdes E, et al. From depressive symptoms to depressive disorders: the relevance of thresholds. The British Journal of Psychiatry. 2010;196(5):365-371.

19. Triadó C, Villar F. Psicología de la Vejez. Madrid: Alianza Editorial; 2014.

20. Karimzade A, Besharat MA. An investigation of the relationship between personality dimensions and stress coping styles. Procedia-Social and Behavioral Sciences. 2011;30:797-802. 
21. Urquijo S, Monchietti A, Krzemien D. Adaptación a la crisis vital de envejecimiento: rol de los estilos de personalidad y de la apreciación cognitiva en adultos mayores. Anales de psicología. 2008;24(2):299-311.

22. Carver C, Connor-Smith J. Personality and Coping. Annual review of psychology. 2010;63:679-704.

23. Matud MP, García MC. Psychological distress and social functioning in elderly Spanish people: a gender analysis. International Journal of Environmental Research and Public Health. 2019;16(3):341-354.

24. Afshar H, Roohafza H, Keshteli AH, et al. Association of personality traits with psychological factors of depression, anxiety, and psychological distress: a community based study. International Journal of Body, Mind and Culture. 2015;2(2):105-114.

25. Nikčevića A, Marino C, Kolubinski DC, et al. Modelling the contribution of the Big Five personality traits, health anxiety, and COVID-19 psychological distress to generalised anxiety and depressive symptoms during the COVID-19 pandemic. Journal of Affective Disorders. 2021;279:578-584
26. O'Shea DM, Dotson VM, Fieo, RA. Aging perceptions and self-efficacy mediate the association between personality traits and depressive symptoms in older adults. International Journal of Geriatric Psychiatry. 2016;32(12):1217-1225.

27. Panayiotou G, Kokkinos CM, Kapsou M. Indirect and direct associations between personality and psychological distress mediated by dispositional coping. The Journal of Psychology:Interdisciplinary and Applied. 2014;148(5):549-567.

28. Lee K, Goo-Churl J, JongEun Y. Consideration of the psychological and mental health of the elderly during COVID-19: a theoretical review. International Journal of Environmental Research and Public Health. 2020;17:1-11.

29. Bao Y, Sun Y, Meng, S, et al. 2019-nCoV epidemic: Address mental health care to empower society. Lancet. 2020;395:37-38.

30. Reardon S. Ebola's mental-health wounds linger in Africa: Healthcare workers struggle to help people who have been traumatized by the epidemic. Nature. 2015;519:13-15. 